\title{
A Simple Analysis Of New York State Tort Reform
}

\author{
Larry Lichtenstein, Canisius College, USA
}

Ronald R. Reiber, Canisius College, USA

\begin{abstract}
In New York State, there has been a rapid increase in personal injury litigation over the recent past. We show empirically that the tort reform that occurred in the 1980s may be, in part, responsible for this phenomenon by increasing the effective structured award that the plaintiff receives. However, despite this generous compensation scheme, some cohorts of plaintiffs may still not receive economic justice.
\end{abstract}

Keywords: economic justice, structured annuity, personal injury litigation

\section{INTRODUCTION}

$\mathscr{D}$ uring the 1980s and 1990s, several state legislatures passed tort reforms because of increasing liability insurance costs. The intention was often to reduce the amount of litigation. Some reforms, however, may have had the opposite unintended effect. It has been argued by forensic economists that mandated methods for compensating plaintiffs in personal injury litigation may distort settlement negotiations, thus increasing the incentives to go to trial (Spizman 2000).

The rapid growth in the number of attorneys nationwide supports the popular impression that litigation has grown dramatically. In recent years, the growth rate in the number of attorneys has exceeded the growth rate of the population.

The number of attorneys in the U.S. increased from 355,242 in 1970 to 954,000 in 2004, a $2.95 \%$ per year increase. The U.S. population over this same time period increased from 203 million to 296 million, a 1.12\% per year increase. This phenomenon is especially pronounced in New York State where the number of attorneys increased from 48,312 in 1970 to 142,538 in 2004, a 3.22\% per year increase. Over this same time period, New York's population only increased from 18.237 million to 19.190 million, a $.15 \%$ per year increase (Statistical Abstracts).

This increase in the number of attorneys may be caused by a change in the magnitude of compensation attorneys receive for representing plaintiffs at trial which is a fixed percentage of the award. There is a greater incentive to litigate if the calculation of compensation results in an overstatement of economic loss. If an injured person incurs losses that have a true present value of $\$ X$ and that person is awarded an amount exceeding $\$ X$, then over-compensation occurs. If this procedure is systematic rather than occasional, it will be in both the injured party's and attorney's self interest to litigate. Lawsuits of marginal value may be undertaken because the expected financial return outweighs the risk.

During the mid-1980's, the New York State legislature passed the Article 50-B statute that altered the procedure for reducing future economic damages to present value. This statute has been controversial since its inception. Several authors have argued that Article 50-B has a pro-plaintiff bias. Wolkoff and Hanushek (1995) and Lambrinos and Harmon (1995) examine hypothetical situations in which they compare the present value of the award under 50-B with the true present value of damages suffered by the plaintiff. They find that under the vast majority of cases, Article 50-B over-compensates the plaintiff by 60 to 140 percent. Spizman and Dunn-Schmitt (2000) have mathematically demonstrated that the present value of the 50-B structure is always greater than the true 
present value of damages suffered by the plaintiff.

The Public Policy Institute of New York State (“An Accident and a Dream”, 1995) also note that this wellintentioned reform increased legal costs. We agree with these conclusions. In this paper, we illustrate the nature of the over-compensation through a numerical example and then explore the factors that influence the degree of overcompensation under 50-B.

\section{A NUMERICAL ILLUSTRATION}

Jury awards are typically comprised of a past and a future component for a variety of categories of loss, such as wages, fringe benefits, pain and suffering, and medical expenses. For expositional ease, we consider a potential jury award made solely for future medical expenses that will be incurred by the plaintiff.

Suppose the medical expert will testify that the plaintiff will incur medical expenses over a 20 year period with medical expenses of $\$ 100,000$ in year one. Furthermore, medical expenses will grow by $4.5 \%$ per year over this period. Future lifetime medical expenses are shown in Table 1 in the amount of $\$ 3,137,142$. If the award for future medical expenses is given as a lump-sum payment, economic theory requires that future losses be reduced to their present values. Assuming a market interest rate of 5\%, the present value of these cash flows amounts to $\$ 1,821,007$, as shown in Table 1 . If $\$ 1,821,007$ were invested today at a $5 \%$ interest rate, the plaintiff would be able to pay for the costs of future medical care over the next 20 years.

Table 1: True Present Value

\begin{tabular}{ccc}
\hline Year & $\frac{\text { Actual Cost }}{\$ 100,000}$ & $\frac{\text { Present Value }}{\$ 95,238}$ \\
2 & $\$ 104,500$ & $\$ 94,785$ \\
3 & $\$ 109,203$ & $\$ 94,333$ \\
4 & $\$ 114,117$ & $\$ 93,884$ \\
5 & $\$ 119,252$ & $\$ 93,437$ \\
6 & $\$ 124,618$ & $\$ 92,992$ \\
7 & $\$ 130,226$ & $\$ 92,549$ \\
8 & $\$ 136,086$ & $\$ 92,108$ \\
9 & $\$ 142,210$ & $\$ 91,670$ \\
10 & $\$ 148,610$ & $\$ 91,233$ \\
11 & $\$ 155,297$ & $\$ 90,799$ \\
12 & $\$ 162,285$ & $\$ 90,367$ \\
13 & $\$ 169,588$ & $\$ 89,936$ \\
14 & $\$ 177,220$ & $\$ 89,508$ \\
15 & $\$ 185,194$ & $\$ 89,082$ \\
16 & $\$ 193,528$ & $\$ 88,658$ \\
17 & $\$ 202,237$ & $\$ 88,235$ \\
18 & $\$ 211,338$ & $\$ 87,815$ \\
19 & $\$ 220,848$ & $\$ 87,397$ \\
20 & $\$ 230,786$ & $\$ 86,981$ \\
& $\$ \mathbf{3 , 1 3 7 , 1 4 2}$ & $\$ \mathbf{1 0 2 1 , 0 0 7}$ \\
\hline
\end{tabular}

Article 50-B does not provide a structured settlement based entirely on trial testimony. The procedure is rather convoluted. The following steps are employed. First, future lifetime medical expenses are computed at trial $(\$ 3,137,142)$. Second, $\$ 250,000$ of the future damages is paid as a lump sum. Third, an annuity is then created for the remaining amount by subtracting $\$ 250,000$ from the $\$ 3,137,142$ total award, yielding $\$ 2,887,142$. Fourth, this remainder is divided by the time frame over which the jury made the award (20 years), yielding a first year annuity payment of $\$ 144,357$. This is shown in Table 2. 
Table 2: Calculation of First-year Annuity under Article 50-B

Actual total lifetime cost:
- First $\$ 250,000$ paid now:
Amount to be annuitized:
/ Number of years:
First year annuity:

$\$ 3,137,142$
$\$ 250,000$
$\$ 2,887,142$
$\underline{20}_{144,357}$

Fifth, although medical inflation has already been accounted for, the statute requires the first year annuity of $\$ 144,357$ with an incremental increase of $4 \%$ per year over the entire period, as shown in Table 3 . The present value of this annuity amounts to $\$ 2,514,538$ as shown in Table 3. Under $50-\mathrm{B}$, the combined present value is $\$ 250,000+\$ 2,514,538=\$ 2,764,538$. The Article 50-B statute results in a pro-plaintiff bias since the present value of the award under 50-B exceeds the true present value by $\$ 943,531(\$ 2,764,538-\$ 1,821,007)$. The percentage by which the present value under 50-B exceeds the true present value of losses (percent overpayment) is $\$ 943,531 /$ $\$ 1,821,007=51.8 \%$.

Table 3: Present Value under Article 50-B

\begin{tabular}{|c|c|c|}
\hline Year & Annuity & Present Value \\
\hline 1 & $\$ 144,357$ & $\$ 137,483$ \\
\hline 2 & $\$ 150,131$ & $\$ 136,174$ \\
\hline 3 & $\$ 156,137$ & $\$ 134,877$ \\
\hline 4 & $\$ 162,382$ & $\$ 133,592$ \\
\hline 5 & $\$ 168,877$ & $\$ 132,320$ \\
\hline 6 & $\$ 175,633$ & $\$ 131,060$ \\
\hline 7 & $\$ 182,658$ & $\$ 129,811$ \\
\hline 8 & $\$ 189,964$ & $\$ 128,575$ \\
\hline 9 & $\$ 197,563$ & $\$ 127,351$ \\
\hline 10 & $\$ 205,465$ & $\$ 126,138$ \\
\hline 11 & $\$ 213,684$ & $\$ 124,936$ \\
\hline 12 & $\$ 222,231$ & $\$ 123,747$ \\
\hline 13 & $\$ 231,120$ & $\$ 122,568$ \\
\hline 14 & $\$ 240,365$ & $\$ 121,401$ \\
\hline 15 & $\$ 249,980$ & $\$ 120,245$ \\
\hline 16 & $\$ 259,979$ & $\$ 119,099$ \\
\hline 17 & $\$ 270,378$ & $\$ 117,965$ \\
\hline 18 & $\$ 281,193$ & $\$ 116,842$ \\
\hline 19 & $\$ 292,441$ & $\$ 115,729$ \\
\hline \multirow[t]{2}{*}{20} & $\$ 304,139$ & $\$ 114,627$ \\
\hline & & $\overline{\$ 2,514,538}$ \\
\hline & $\$ 2,514,538$ \\
\hline \multicolumn{2}{|c|}{ + Lump-sum payment $\$ 250,000$ : } & $\$ 250,000$ \\
\hline \multicolumn{2}{|c|}{ Total 50-B Present Value: } & $\$ 2,764,538$ \\
\hline
\end{tabular}

\section{FACTORS THAT INFLUENCE PERCENT OVERPAYMENT}

The percent overpayment is not fixed but rather a function of the age of the plaintiff as well as medical inflation and discount rates. Let $\mathrm{T}=$ number of years into the future that the plaintiff will incur medical expenses, $\mathrm{m}$ $=$ medical inflation rate, and $\mathrm{d}=$ discount rate. The first year medical expense is assumed to be $\$ 100,000^{1}$. The true present value of the future medical expenses $\left(\mathrm{PV}_{\text {True }}\right)$ can be expressed $\mathrm{as}^{2}$ : 


$$
\mathrm{PV}_{\text {True }}=\left(\frac{100,000}{1+m}\right)\left[\frac{1-\frac{1}{\left(\frac{1+d}{1+m}\right)^{T}}}{\left(\frac{d-m}{1+m}\right)}\right]
$$

The present value of all payments made by the defendant under 50-B $\left(\mathrm{PV}_{50 \mathrm{~B}}\right)$ can be expressed $\mathrm{as}^{3}$ :

$\mathrm{PV}_{50 \mathrm{~B}}=\frac{\left\{100,000\left[\frac{(1+m)^{T}-1}{m}\right]-250,000\right\}\left[1-\frac{1}{\left(\frac{1+d}{1.04}\right)^{T}}\right]}{1.04 T}+250,000$

The percent overpayment (PO) can be expressed as:

$\mathrm{PO}=$ Percent Overpayment $=\frac{P V_{50 B}-P V_{\text {True }}}{P V_{\text {True }}}=\frac{P V_{50 B}}{P V_{\text {True }}}-1$

This may be rewritten as (4).

$$
\frac{\left\{100,000\left[\frac{(1+m)^{T}-1}{m}\right]-250,000\right\}\left[\frac{\left.1-\frac{1}{\left(\frac{1+d}{1.04}\right)^{T}}\right]}{1.04 T}+250,000\right.}{\left(\frac{100,000}{1+m}\right)\left[\frac{\left.1-\frac{1-.04}{1.04}\right)}{\left(\frac{1+d}{1+m}\right)^{T}}\right]}-1
$$

We are interested in examining how PO is influenced by changes in the variables $\mathrm{T}, \mathrm{m}$ and $\mathrm{d}$. Given the difficulty of finding and signing the following partial derivatives: 


$$
\frac{\partial P O}{\partial T}, \frac{\partial P O}{\partial m}, \text { and } \frac{\partial P O}{\partial d},
$$

We have chosen to draw inferences about these partial derivatives by varying the values for each variable, one at a time, holding the values of the other variables constant. In Table 4, we compute percent overpayment for various levels of $\mathrm{m}, \mathrm{T}$ and $\mathrm{d}$. We vary the discount rate and medical inflation rate from $4 \%$ to $7 \%$. We also vary the time horizon of the future payments from 10 to 50 years in 10 year increments. The evidence provided in Table 4

suggests $\frac{\partial P O}{\partial T}>0, \frac{\partial P O}{\partial m}>0$, and $\frac{\partial P O}{\partial d}>0$.

Table 4: Percent Overpayment

\begin{tabular}{|c|c|c|c|c|}
\hline \multirow[b]{2}{*}{ Medical Inflation } & \multicolumn{4}{|c|}{10 Years Discount Rate } \\
\hline & $4.0 \%$ & $5.0 \%$ & $6.0 \%$ & $7.0 \%$ \\
\hline $4.0 \%$ & $21 \%$ & $\overline{22 \%}$ & $\overline{24 \%}$ & $\overline{25 \%}$ \\
\hline $5.0 \%$ & $21 \%$ & $23 \%$ & $24 \%$ & $26 \%$ \\
\hline $6.0 \%$ & $22 \%$ & $23 \%$ & $25 \%$ & $26 \%$ \\
\hline \multirow[t]{2}{*}{$7.0 \%$} & $22 \%$ & $24 \%$ & $25 \%$ & $27 \%$ \\
\hline & \multicolumn{4}{|c|}{20 Years Discount Rate } \\
\hline Medical Inflation & $4.0 \%$ & $5.0 \%$ & $6.0 \%$ & $7.0 \%$ \\
\hline $4.0 \%$ & $\overline{49 \%}$ & $51 \%$ & $52 \%$ & $54 \%$ \\
\hline $5.0 \%$ & $51 \%$ & $53 \%$ & $55 \%$ & $57 \%$ \\
\hline $6.0 \%$ & $53 \%$ & $55 \%$ & $57 \%$ & $59 \%$ \\
\hline \multirow[t]{2}{*}{$7.0 \%$} & $55 \%$ & $57 \%$ & $60 \%$ & $62 \%$ \\
\hline & \multicolumn{4}{|c|}{30 Years Discount Rate } \\
\hline Medical Inflation & $4.0 \%$ & $\frac{0.10}{5.0 \%}$ & $6.0 \%$ & $7.0 \%$ \\
\hline $4.0 \%$ & $87 \%$ & $89 \%$ & $90 \%$ & $92 \%$ \\
\hline $5.0 \%$ & $92 \%$ & $95 \%$ & $98 \%$ & $100 \%$ \\
\hline $6.0 \%$ & $97 \%$ & $101 \%$ & $105 \%$ & $109 \%$ \\
\hline \multirow[t]{2}{*}{$7.0 \%$} & $103 \%$ & $108 \%$ & $113 \%$ & $118 \%$ \\
\hline & \multicolumn{4}{|c|}{40 Years Discount Rate } \\
\hline Medical Inflation & $4.0 \%$ & $5.0 \%$ & $\underline{6.0} \%$ & $\underline{7.0 \%}$ \\
\hline $4.0 \%$ & $138 \%$ & $139 \%$ & $\overline{141 \%}$ & $\overline{142 \%}$ \\
\hline $5.0 \%$ & $149 \%$ & $153 \%$ & $158 \%$ & $162 \%$ \\
\hline $6.0 \%$ & $161 \%$ & $168 \%$ & $176 \%$ & $183 \%$ \\
\hline \multirow[t]{2}{*}{$7.0 \%$} & $172 \%$ & $183 \%$ & $194 \%$ & $205 \%$ \\
\hline & \multicolumn{4}{|c|}{ 50 Years Discount Rate } \\
\hline Medical Inflation & $4.0 \%$ & $5.0 \%$ & $6.0 \%$ & $7.0 \%$ \\
\hline $4.0 \%$ & $206 \%$ & $207 \%$ & $208 \%$ & $210 \%$ \\
\hline $5.0 \%$ & $228 \%$ & $236 \%$ & $243 \%$ & $251 \%$ \\
\hline $6.0 \%$ & $251 \%$ & $265 \%$ & $280 \%$ & $295 \%$ \\
\hline $7.0 \%$ & $273 \%$ & $295 \%$ & $318 \%$ & $343 \%$ \\
\hline
\end{tabular}

\section{CONCLUSION}

Under statute 50-B, we have demonstrated, through an illustration, that the value of PO is always positive. In New York State, therefore, if plaintiffs prevail at trial, the structured award received will exceed the true economic loss and increase the incentive to litigate relative to states that structure the award based on the true present value. This explains, in part, the more rapid growth of attorneys in New York State than nationwide. 
Clearly, the incentive to litigate in New York State is greater than in other states. This incentive is most pronounced when the time horizon is longest, which occurs for young plaintiffs. For example, given a medical inflation rate and discount rate of $6 \%$, there will be an overpayment of $25 \%$ for a plaintiff with a life expectancy of 10 years. This contrasts with an overpayment of $280 \%$ for a plaintiff with a 50 -year life expectancy. We would expect the demographic composition of the litigation pool in New York State to be more heavily weighted with younger individuals. Similarly, we would expect the incentive to litigate in New York State to be greater during periods of high inflation, which results in high medical inflation and discount rates.

Finally, there is the issue of justice for the plaintiff. If the defendant paid attorney fees in addition to the economic damages, a PO of $0 \%$ would make the plaintiff whole; that is, the plaintiff would receive the necessary amount of dollars to pay future medical expenses, but in New York State, the plaintiff is obligated to pay attorney fees out of the award. Assuming that attorney fees are 1/3 of the award, a PO of 50\% is necessary to make the plaintiff whole. For example, if the true present value is $\$ 100$, a 50-B present value of $\$ 150$ allows for an attorney fee of $\$ 50$ and provides the plaintiff with the remainder of $\$ 100$. We see from Table 4 that a percent overpayment of approximately $50 \%$ occurs when the time horizon is 20 years. This suggests that even in a progressive state, such as New York, older plaintiffs (those with life expectancies of fewer than 20 years) will not receive adequate compensation to make them whole. Only younger plaintiffs will receive an award that just compensates or overcompensates them for their injury.

\section{AUTHOR INFORMATION}

Ronald Reiber, Ph.D., is Associate Professor of Economics and Finance at Canisius College. He received his doctorate in Economics from the University of Arizona. His research interests include investments and litigation economics.

Larry Lichtenstein, Ph.D., is Associate Professor of Economics and Finance at Canisius College. He received his doctorate in Economics from the State University of New York at Binghamton. His research interests include microeconomics and the housing market.

\section{ENDNOTES}

${ }^{1}$ It can be shown that, for all intents and purposes, the analysis is invariant with respect to the magnitude of the first year payment.

${ }^{2}$ This expression is valid as long as $\mathrm{d} \neq \mathrm{m}$. When $\mathrm{d}=\mathrm{m}, \mathrm{PV}_{\text {True }}=[\mathrm{FYC} /(1+\mathrm{m})] \mathrm{T}$.

${ }^{3}$ This expression is valid as long as $\mathrm{d} \neq .04$. When $\mathrm{d}=.04$, a similar adjustment to that shown in Endnote 1 is made.

\section{REFERENCES}

1. “An Accident and a Dream", The Public Policy Institute of New York State, Inc. 1998.

2. $\quad$ Civil Practice and Law Rules (CPLR) Articles 50(a) (CPLR 5031-5039) in 1985 and 50(b) (CPLR 50415049) in 1986.

3. Ireland, Thomas R., “A Comment on 'One More Time: New York’s Structured Settlement Statutes, Rent Seeking and the Pro-Plaintiff Bias,' "Journal of Forensic Economics, Fall 2003, 16(3), 301-304.

4. Riccardi, Anthony H., "A Response to Rent Seeking in New York State's Structured

5. Judgment Settlement Statutes," Journal of Forensic Economics, Fall 2001, 14(3), 273-292.

6. __ "A Comment on "One More Time: New York's Structured Settlement Statutes, Rent Seeking and the Pro-Plaintiff Bias"," Journal of Forensic Economics, Fall 2003, 16(3), 305-307.

7. Rohring v City of Niagara Falls, No 117 Court of Appeals of New York, 84 N.Y. 2d 60; 683 N.E. 2d 62 1994, Lexis 1427; 614 N.Y.S. $2 d 714$

8. Spizman, Lawrence M., and Elizabeth Dunn Schmitt, "The Unintended Consequences of Tort Reform: Rent Seeking in New York State's Structured Settlements Statutes," Journal of Forensic Economics, Winter 2000, 13(1), 29-48.

9. ___ and Frederic G. Floss, "One More Time: New York's Structured Settlement Statutes, Rent

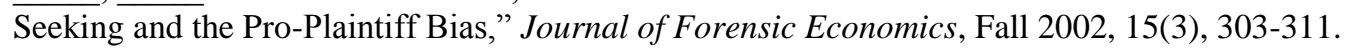




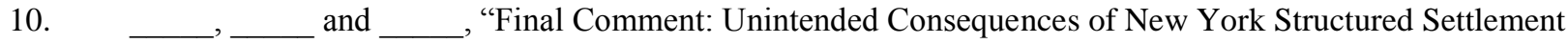

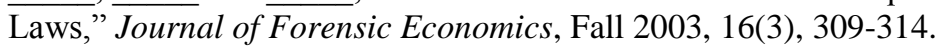

11. Statistical Abstract of the United States, 1971 and 2005; U.S. Department of Commerce, Economics and Statistics Administration, Bureau of the Census.

12. Wolkoff, Michael and Eric Hanushek, "The Economics of Structured Judgments Under CPLR 50-B," Buffalo Law Review, 1995, 43, 563-582. 


\section{NOTES}

